

\title{
Dinâmica de nutrientes entra águas intersticiais de manguezais e águas estuarinas adjacentes, Baixada Santista (SP)
}

\section{Felipe Filtrin Pessanha*, Wanilson Luiz-Silva, Wilson Machado, Alice Bosco-Santos}

\section{Resumo}

Concentrações de fosfato e sílica em águas intersticiais e de superfície de estuários da Baixada Santista (SP) sugerem exportação de nutrientes do continente para o oceano, cuja origem pode estar ligada a atividades antrópicas.

Palavras-chave: Poluição, estuário, nutrientes

\section{Introdução}

Atividades antrópicas em estuários podem incrementar os níveis de nutrientes em suas águas. Entender a dinâmica de nutrientes é essencial para a compreensão do funcionamento dos estuários sob pressão de atividades humanas. Um exemplo são os estuários da Baixada Santista (SP) impactados por um parque industrial desde 1950. Neste estudo, os níveis de fosfato e sílica em águas intersticiais (água dos poros dos sedimentos) e de superfície foram investigados na interface entre o manguezal e os canais estuarinos, com o objetivo de avaliar a flutuação espacial destes nutrientes e possíveis influências antrópicas.

\section{Métodos}

Amostras de águas intersticiais foram coletadas (agosto/2015) por diálise (coletores peeper; BoscoSantos, 2015) segundo transversais com quatro pontos equidistantes (Fig. 1) nos estuários dos rios Morrão, Cubatão e Branco, Baixada Santista (SP). Águas de superfície também foram coletadas nestes locais (marés vazante e cheia), e os parâmetros físico-químicos foram medidos. As concentrações dissolvidas totais de fosfato e sílica foram medidas em amostras filtradas $(0,22 \mu \mathrm{m})$ por espectrofotometria UV-vis (APHA, 1992).

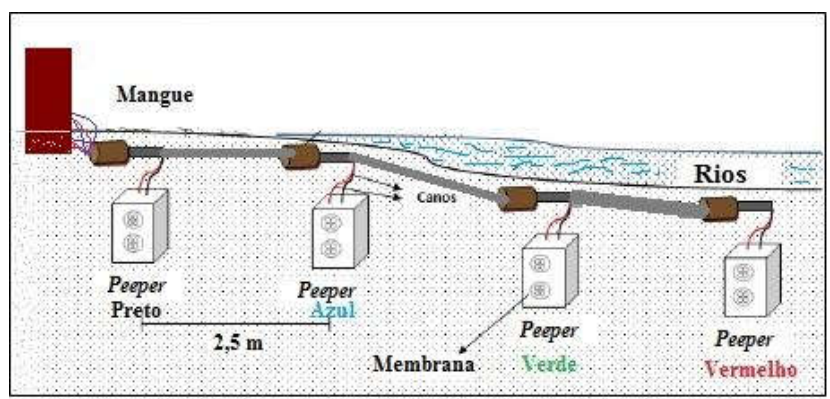

Figura 1: Esquema da disposição espacial dos peepers para a coleta de águas intersticiais.

\section{Resultados e Discussão}

As concentrações de fosfato e sílica são mostradas na Tabela 1. Em geral, as concentrações destes nutrientes foram maiores nas águas intersticiais (maior tempo de residência) do que nas águas de superfície. As águas de superfície apresentaram concentrações contrastantes durante o regime de maré, e nos rios localizados mais próximos às atividades industriais, concentrações de fosfato superiores na maré vazante indicaram forte contribuição continental. Entre os rios, os níveis mais altos de fosfato em ambas as águas estudadas coincidiram com a proximidade de indústria de fertilizantes, sendo superiores no rio Morrão > Cubatão $\geq$ Branco. Para a sílica, o mesmo comportamento foi observado nas águas superficiais (Morrão > Cubatão $\geq$ Branco), mas não nas intersticiais (Branco > Morrão > Cubatão). Não foram observadas variações nos níveis de nutrientes, pH (em média 6,6) e salinidade (média de 26,8) ao longo das transversais de águas intersticiais estudadas. Por outro lado, os valores de Eh indicaram ambiente subóxico nas águas intersticiais dos rios Morrão e Cubatão (média de $248 \mathrm{mV}$ ), e redutor no rio Branco (em média $370 \mathrm{mV}$ ). Nas às águas de superfície de todos os rios, o $\mathrm{pH}$ foi levemente alcalino nas marés vazante (média de 7,3 ) e cheia (média de 7,6), marcadas por salinidades de 27 e 32, respectivamente, e ambiente oxidante (média geral de $456 \mathrm{mV}$ ). Os resultados deste estudo indicaram contribuição das atividades industriais nos níveis de nutrientes das águas investigadas, especialmente, nas de superfície do rio Morrão. Maior proximidade de indústrias (fertilizantes, siderurgia) corrobora o aporte antrópico. Os maiores valores de fosfato e sílica nas águas da maré vazante indicaram os estuários da Baixada Santista como exportadores de nutrientes para a Baía de Santos, cujos efeitos precisam ser investigados em estudos futuros.

Tabela 1: Concentrações de fosfato e sílica ( $\mathrm{mg} / \mathrm{L})$ referentes aos estuários estudados em águas intersticiais (esquema Fig. 1) e de superfície ( $M V$ e MC = marés vazante e cheia, respectivamente).

\begin{tabular}{cccccccc}
\hline Amostras & \multicolumn{2}{c}{ Rio Morrão } & \multicolumn{2}{c}{ Rio Cubatão } & \multicolumn{2}{c}{ Rio Branco } \\
\hline Peeper & Fosfato & Sílica & Fosfato & Sílica & Fosfato & Sílica \\
Preto & 12,0 & 28,0 & 9,22 & 23,1 & 10,6 & 50,7 \\
Azul & 20,0 & 32,5 & 12,0 & 15,2 & 12,1 & 46,8 \\
Verde & 20,3 & 27,3 & 6,58 & 19,6 & 6,91 & 44,6 \\
Vermelho & 7,84 & 28,7 & 6,17 & 10,2 & 6,39 & 48,6 \\
\hline Superfície (MV) & 7,07 & 7,86 & 3,45 & 4,52 & 0,98 & 4,04 \\
Superfície (MC) & 4,03 & 5,33 & 2,48 & 3,42 & 1,05 & 3,90 \\
\hline
\end{tabular}

APHA (1992). Standard Methods for the Examination of Water and Wastewater. Washington: APHA.

Bosco-Santos, A. (2015). Elementos terras raras e traçadores isotópicos em estuários subtropicais: uma abordagem geoquímica da transferência de metais à biota. Tese (Doutorado em Ciências) - Universidade Estadual de Campinas. 